\title{
METÁSTASIS DE MELANOMA CUTÁNEO EN VESÍCULA BILIAR*
}

\author{
Drs. Óscar Tapia E. ${ }^{1}$, Francisco Jofré C. ${ }^{2}$, Xabier de Aretxabala U. ${ }^{2}$ \\ Departamento de Anatomía Patológica. Facultad de Medicina. Universidad de La Frontera. Temuco. \\ 2 Servicio de Cirugía, Hospital Fuerza Aérea de Chile. Santiago. \\ Chile.
}

\section{Cutaneous melanoma metastasis in gallbladder}

Mujer de 58 años con antecedentes de hipertensión arterial, hipotiroidismo en tratamiento y melanoma maligno (MM) cutáneo dorsal operado el año 2010 cuyo informe histopatológico reveló un MM de 1,25 mm de espesor según Breslow y nivel IV de Clark con estudio de bordes quirúrgicos negativos. El estudio de diseminación no demostró lesiones secundarias.

La paciente evoluciona asintomática pesquisándose en ecotomografía abdominal de 2013 un engrosamiento parietal vesicular de aproximadamente 3,1 $\mathrm{cm}$ de diámetro mayor con señal al doppler color y ausencia de litiasis (Figura 1A). El TC de abdomen no mostró otras lesiones. Con estos hallazgos se decide efectuar colecistectomía abierta.

En la pieza operatoria se observó masa endoluminal polipoídea pardo negruzca de $3,5 \times 2,4 \mathrm{~cm}$ (Figura 1B). El estudio histopatológico demostró infiltración de la pared vesicular por neoplasia conformada por células redondeadas balonadas con núcleos pleomórficos, hipercromáticos y vesiculosos con nucléolo prominente, figuras mitóticas atípicas y abundante pigmento pardusco de melanina (Figura $1 \mathrm{C}$ y 1D), compatible con metástasis de MM.

Las metástasis en la vesícula biliar son infrecuentes y rara vez sospechadas antes de la cirugía. El melanoma maligno (MM) representa el tumor metastásico más frecuente en la vesícula biliar (30-60\%) mientras que la frecuencia de metástasis vesicular en pacientes con MM fluctúa entre 4-20\%. Estos pacientes son habitualmente asintomáticos. La ecografía abdominal representa el método diagnóstico de mayor utilidad, pudiendo observarse ausencia de cálculos y engrosamiento parietal o masa intraluminal hiperecoica, comúnmente $>1 \mathrm{~cm}$, con mínima sombra acústica y señal en el doppler color. El tratamiento en estos casos aún no está estandarizado y dependerá de la extensión de la enfermedad y estado clínico del paciente, incluyéndose entre las opciones la cirugía, quimioterapia y terapias biológicas. El pronóstico a pesar del tratamiento es pobre con promedios de supervivencia de 8,4 meses.

\footnotetext{
*Recibido el 15 de abril de 2014 y aceptado para publicación el 12 de junio de 2014.
}

Los autores no refieren conflictos de interés.

Correspondencia: Dr. Óscar Tapia E. otescalona@gmail.com 


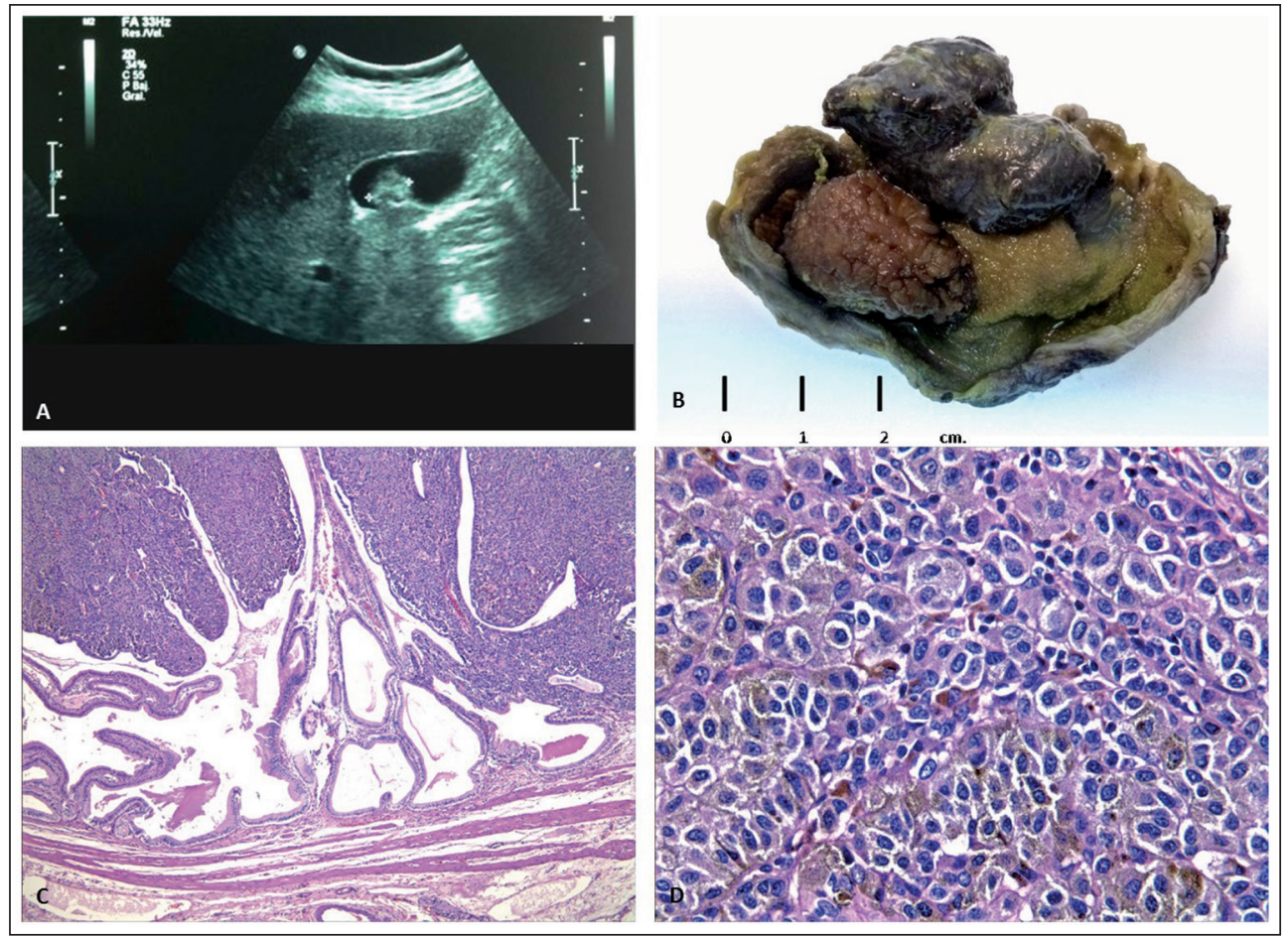

Figura 1. A. Ecotomografía abdominal. B. Pieza extirpada. C. y D. Microscopia.

\section{Referencias}

1. Vernadakis S, Rallis G, Danias N, Serafimidis C, Christodoulou E, Troullinakis M, et al. Metastatic melanoma of the gallbladder: an unusual clinical presentation of acute cholecystitis. World J Gastroenterol. 2009;15:3434-6.

2. Samplaski MK, Rosato EL, Witkiewicz AK, Mastrangelo MJ, Berger AC. Malignant melanoma of the gallbladder: a report of two cases and review of the literature. J Gastrointest Surg. 2008;12:1123-6. 